\title{
A NEW DISEASE OF ORCHIDS IN PUERTO RICO: PYTHIUM BLACK ROT
}

\section{A. ALVAREZ GARCIA ${ }^{1}$}

Reports of a black rot of orchids, (Laelio-Cattleya and Cattleya spp.) growing in greenhouses and outdoors in the Metropolitan Area, were received early in November 1949.

The weather was chilly and humid during the month of November and December 1949, and through February and March 1950. The temperature during November and December varied from.a low of $16^{\circ} \mathrm{C}$., during the night to a high of $26^{\circ} \mathrm{C}$. during the day. At the end of February, 1950 temperatures from 20 to $24^{\circ} \mathrm{C}$. at night, and 26 to $30^{\circ} \mathrm{C}$. during the day were prevalent. The average relative humidity was around 90 percent most of the time because of frequent rains and foggy weather.

\section{CHARACTERISTICS OF THE DISEASE}

Symptoms: The disease is characterized by the development of black spots of variable sizes on pseudobulbs, leaves, stem, and roots. At first the lesions on the pseudobulbs, are recognized as dull green, minute spots. These enlarge and become light yellow as they grow older. The diseased areas finally turn brown or black. The lesions spread very rapidly especially on young, succulent pseudobulbs. The longitudinal rate of enlargement is from 2 to 3 inches per day, extending also around the pseudobulbs.

The infections are confined to the parenchyma tissue, and are characterized by the disorganization and decay of the cells without foul odors. The fibrovascular bundles remain entire, though they become dark and appear as fibers or threads within the rotted parenchyma tissues. The infected pseudobulbs rot in 12 to 14 days in tender pseudobulbs after the symptoms of infection are shown. In older pseudobulbs, the rate of development of the infection is delayed but eventually they decay completely.

The lesions start as small, dull spots or narrow streaks on the leaves. These lesions appear the margins and tips and other times scattered over the blade. Spots are frequently found on the midrib and at the base of the leaf. The enlargement of the disease areas on the leaves is not as rapid as in young pseudobulbus. Apparently, the higher moisture content of the pseudobulbs accounts for the differential growth rate of the pathogen. Diseased leaves are shed prematurely when the infections are produced at the base of the leaves, or at the tip of the pseudobulbs. When the environment is humid for days, the pseudobulbs and leaves become soft and rot.

1 Plant Pathologist, Head of the Department Agricultural Experiment Station, University of Puerto Rico, Rio Piedras, P.R. 
When the weather after infection stays dry the pseudobulbs and leaves become hard. Under humid conditions, stems and roots are attacked by the organism and turn black. Under wet conditions the infection extends from one pseudobulb to another by way of the stem and roots, or by spattered sporangia during rainy weather (fig. 1).

\section{ETIOLOGY}

The pathogen was studied and found to be a strain of Pythium ultimum Trow. Isolates of $P$. ultimum from various diseased Cattleya, Laelio-cattleya

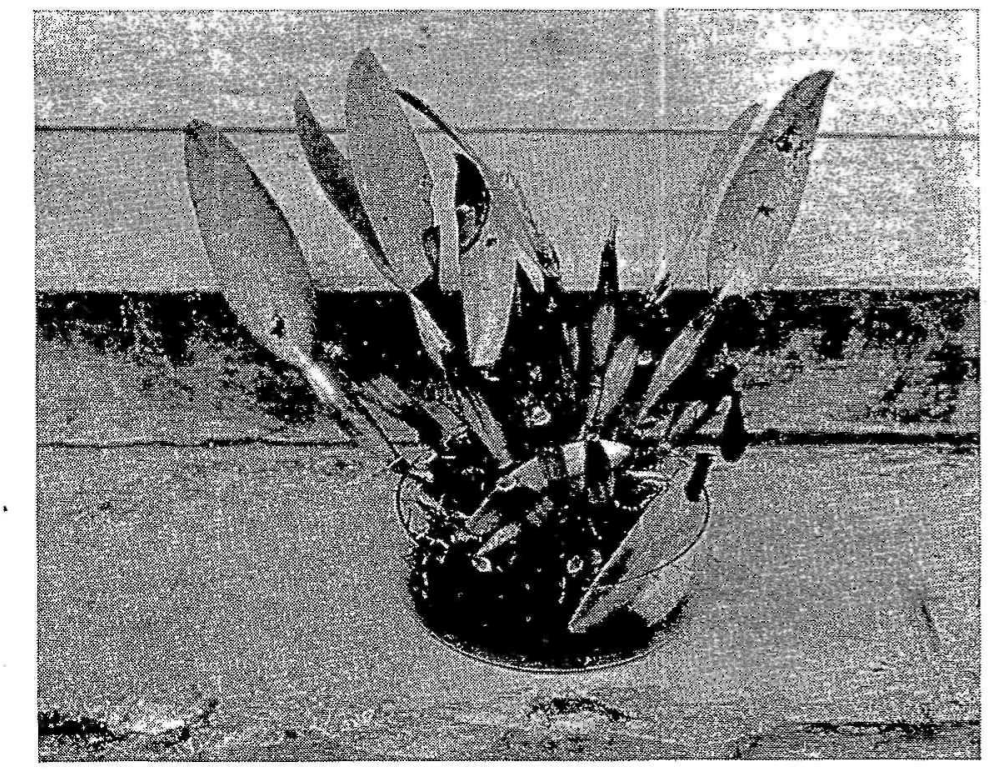
leaves.

FIg. 1.-Cattleya Gigas infected with Pythium ultimum. Inoculation on axis of

and Oncidium showed the association of this fungus with the black rot. The isolates were obtained from infected material supplied by Mr. Ferdinand Méndez, Dr. Luis Fernández, and Mr. Ramón Aboy. Diseased pseudobulbs, leaves, stems, and roots were cleaned of extraneous material by repeated washings with distilled water. Pieces of diseased tissues were immersed in a 10-percent solution of sodium hypochlorite for 5 minutes. Some of these disinfected material was transferred and planted on culture media, in petri dishes. Other pieces were taken aseptically from the innermost tissue of flamed pseudobulbs and leaves and cultured in solid media in petri dishes.

The isolates grew readily in most sugary media and produced a super- 
ficial white, radial growth, that covered the petri-dishes in a day or two after planting. The growth was most rapid at temperature from 26 to $30^{\circ} \mathrm{C}$. The $\mathrm{pH}$ of the cornmeal culture media was 5.26.

In' cornmeal agar the growth was white, light, and radial. The mycelium produced was thick and profusely knobed or gnarled. Sporangia were abundant, solitary, or in chains. The size of catenulated sporangia was variable, some were around 5 to $6 \mu$., others as large as $30 \mu$.; the shape was spherical or papillate. In other cases they were elongated and produced intercalary or at the tips of hyphae (fig. 2).

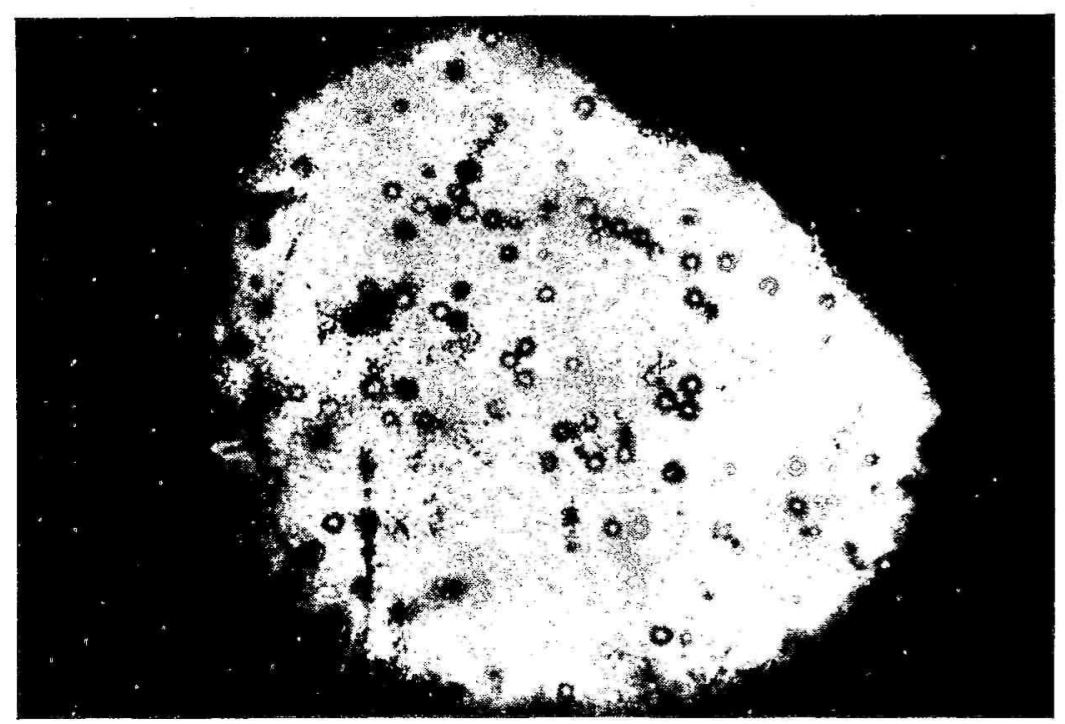

FIG. 2.-Microphotograph of Pythium ultimum, showing sporangia.

Large spherical sporangia were of varying sizes, measuring from 15 to $52 \mu$. in diameter. The sporangial wall was around $2.5 \mu$. The contents of the sporangia was bromnish in color and the coenocentrum was large, subspherical, and refringent.

Oogonia were scanty or absent. They were similar to sporangia in shape and size as well as in other characteristics. They could be distinguished from sporangia only by the presence of antheridia. These are short, sessile, inflated, and upcurved and monoclinous. Germination of sporangia is by germ tubes. Germ-tube formation occur readily at ordinary room temperatures from 26 to $28^{\circ} \mathrm{C}$., but the higher counts are at the lower temperature. Germination is observed at temperatures from 20 to $26^{\circ} \mathrm{C}$. At temperatures above $28^{\circ} \mathrm{C}$, very little or no germination occurred (fig. 3 ).

The organism is soil-harbored. It was found on the Station Grounds 


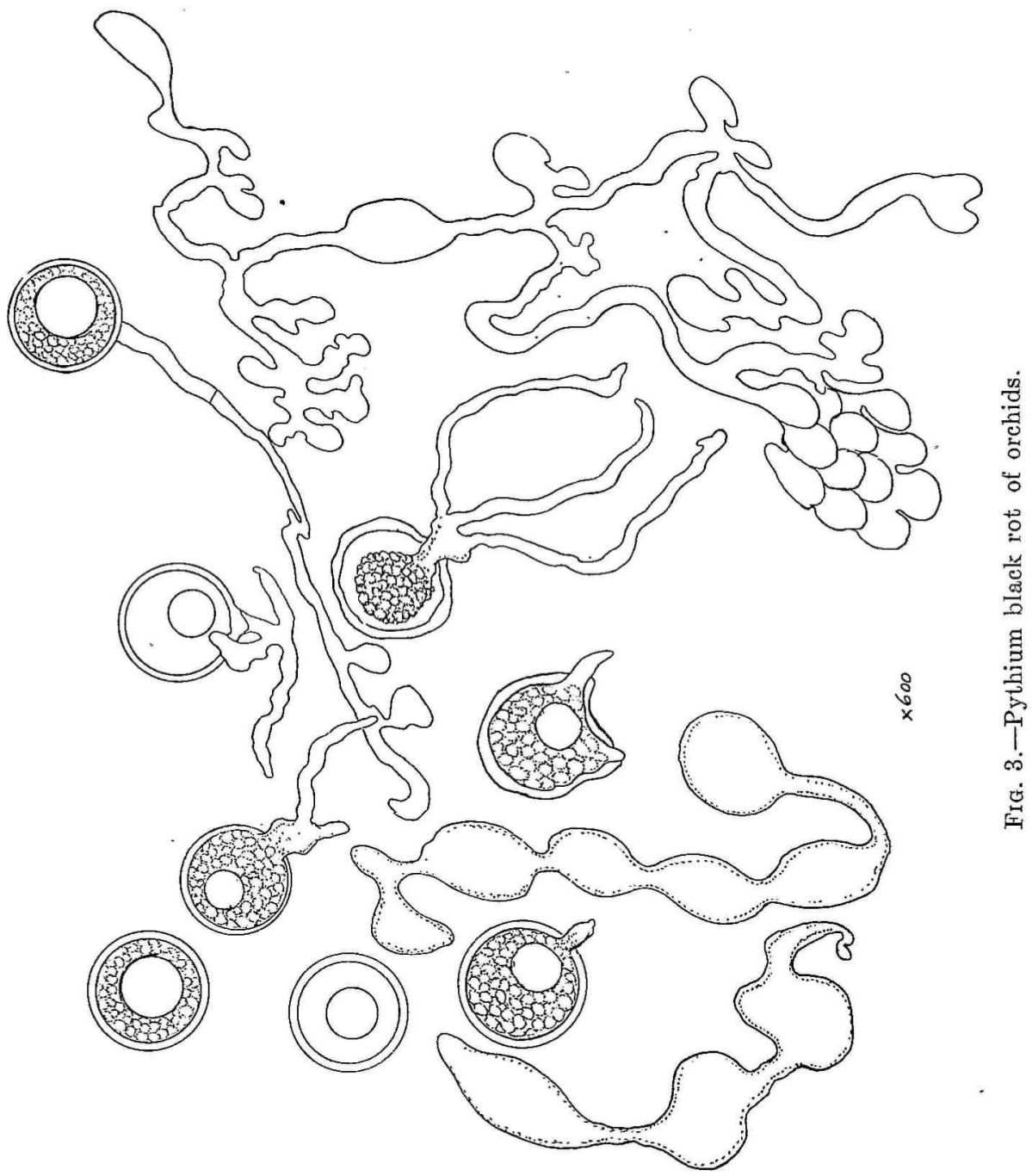


causing damping-off of pepper seedlings in seed beds. The isolates from diseased pepper seedlings compared both in morphology and physiology with the isolates from Cattleya, Laelio-cattleya, and Oncidium.

Rosseti (1) ${ }^{2}$ reported a black rot of Laelia sp. in Brasil, but she did not classify the organism, only mentioning that it was pythiaceous in nature. In this report a similar disease of Cattleya and Vanda from Puerto Rico, and Stanhopea saccata from an unknown place, is mentioned. Porter (2), in Puerto Rico, published a paper dealing with a black rot of Cattleya caused by a Diplodia sp. resembling $D$. natalensis. Artificial inoculation with the organism caused infection on Lyeaste skinneri, Epidendrum nodosum, Oncidium variegatum, $O$ altissimum, Vanilla fragrans, $V$. barbellata, $V$. ecuadori, $V$. pompona, slow development of the infection occurred on Cyrotopodium punctatum, Laelia crispa, L. superbens, Catasetum sp., Gongora sp., Epidembrum lifidum, superbens, Catasetum sp., Gongora sp., Epidembrum lifidum, Lelopsis domingensis.

Limber (3) determined the distribution of pythiaceous black rot of orchids based on interceptions from Venezuela, Colombia, Cuba and England.

In California, Ark and Middleton (4) described a black rot of Cattleya caused by a strain of Pythium ultimum. Sporangia and oospores measures 13.2-29.6 $\mu$. in diameter, with an average of $21.9 \mu$. Infections are produced principally by zoospores. The optimal temperature for growth of the organism is about $28^{\circ} \mathrm{C}$ and for infection around $20^{\circ} \mathrm{C}$. During isolation, a Gloesporium sp. and an organism resembling closely Diplodia natalensis were found. However, none of these organisms were capable of producing black rot of Cattleya even though they were inoculated by wounding the pseudobulbs and leaves. The inoculated plants were kept under a high relative humidity (90 percent) and at a temperature range of from $20^{\circ}$ to $30^{\circ} \mathrm{C}$. One thing was obvious, and that was that the Gloesporium and Diplodia species grew only following previous infection with $P$. ultimum. In regard to $D$. natalensis, it seems that Porter worked with another strain of the fungus. From his publication we cannot get information on the environmental conditions for infection.

\section{EPIPHYTOLOGY}

Cattleya kept in a glass cage, with a constant relative humidity of 90 percent, were inoculated with sporangia from a 15-day culture of $P$. ultimum growing in cornmeal agar with a $\mathrm{pH}$ 5.56. Five-milimeter pieces of agar of a 2-week culture on cornmeal agar with abundant sporangia, were placed on the surface of succulent pseudobulbs. In another test a porangial suspension was sprayed over young leaves. A drop of water

${ }^{2}$ Figures in parentheses refer to Literature Cited p. 135. 


$$
x_{F}
$$


the lesion was slow, and in very old pseudobulbs the lesion took over a month to spread. There is a close association of the degree of succulency of the pseudobulbs and the development of the lesions. (Figs. 5 and 6.)

On the leaves the infection was started as a small water-soaked, dark area which later turned dark (fig. 7). Twice the time was needed to rot

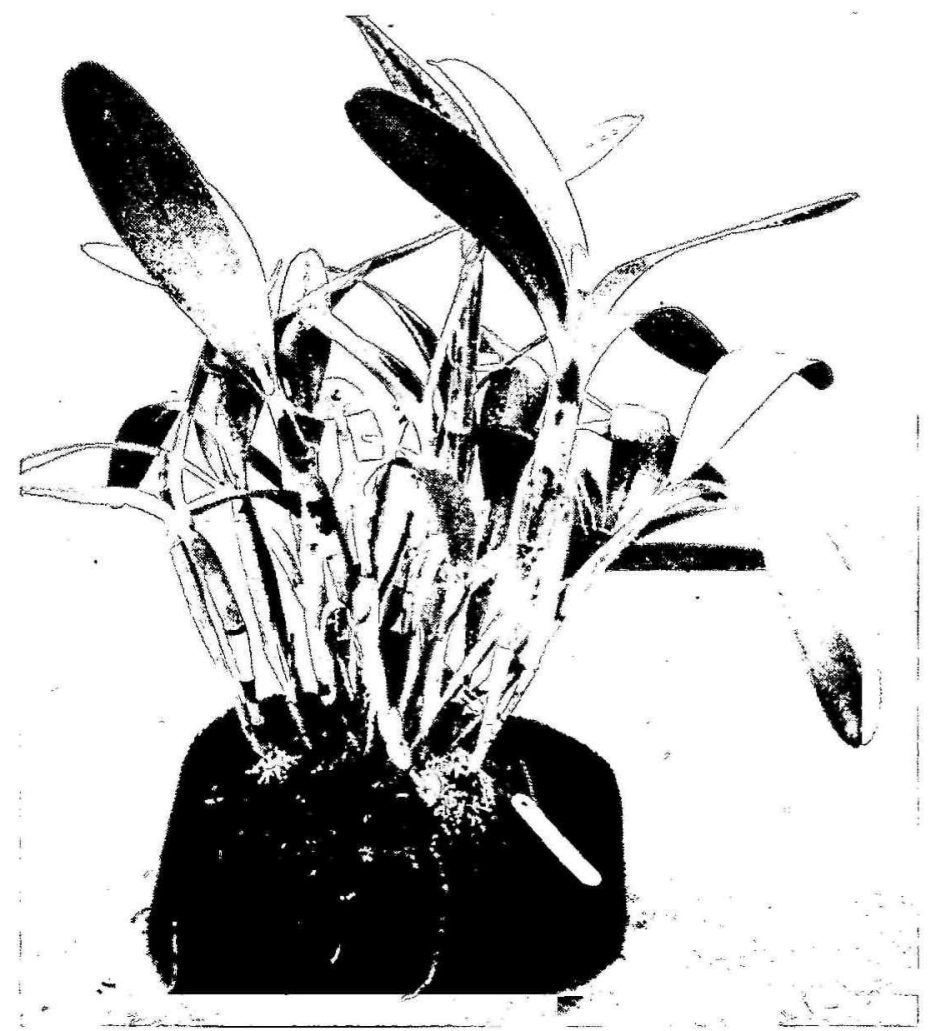

FIG. 5.-Cattleya Bowringiana. General appearance of an orchid plant recently inoculated with Pythium ultimum. Note several pseudobulbs with black-rot lesions.

the leaves when compared with tender pseudobulbs. Infections started at the base of the leaves, spread rapidly along the midribs, and took about 14 days to cover the leaf (fig. 8). Inoculation tests, following Koch's rules, showed the pathogenicity of the various isolates.

High humidity (80 to 90 percent) for at least 2 or 3 days, and temperatures of from $20^{\circ}$ to $30^{\circ} \mathrm{C}$ were farorable for infection.

Cattleya placed in a greenhouse with a low relative humidity, (50 to 60 
per cent) were difficult to infect, unless the pathogen was inoculated through wounds and even so, the infections were arrested from spreading to other pseudobulbs. Infections occurred rapidly in plants left outside and exposed to a high relative humidity. The organism spread by way of infected stem and roots from one pseudobulb to another.

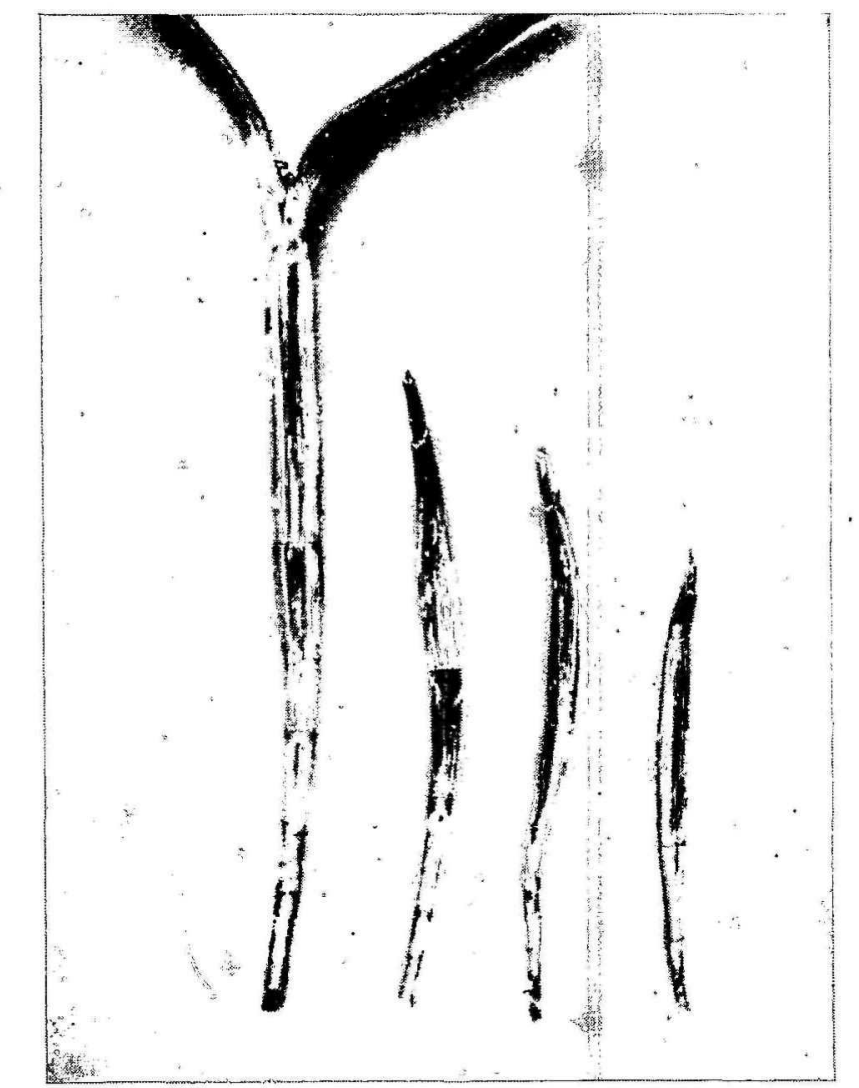

Fig. 6.-Cattleya Bowringiana artificially infected with Pythium ultimum isolated from Cattleya. Infected pseudobulbs.

In testing for resistance, the orchids Cattleya Bowringiana, C. Skinnerii; C. Gigas; C. Mossiae; C. Percivaliana; C. Gaskeliana; C. Trianae and C. Dowiana Aurea were found susceptible to the disease. The lesions on young pseudobulbs appeared in 2 or 3 days after inoculation. Infected pseudobulbs were rotten in 10 to 12 days. The lesions took about twice that time to rot the leaves. 


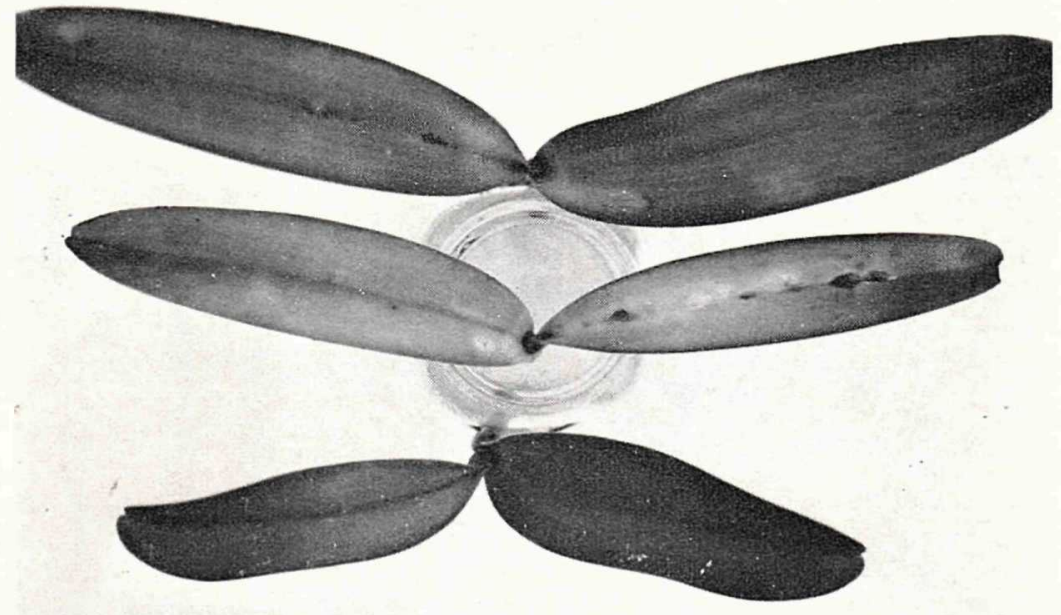

FIg. 7.-Cattleya Bowringiana inoculated with Pythium ultimum. Lower pair of leaves was not inoculated.

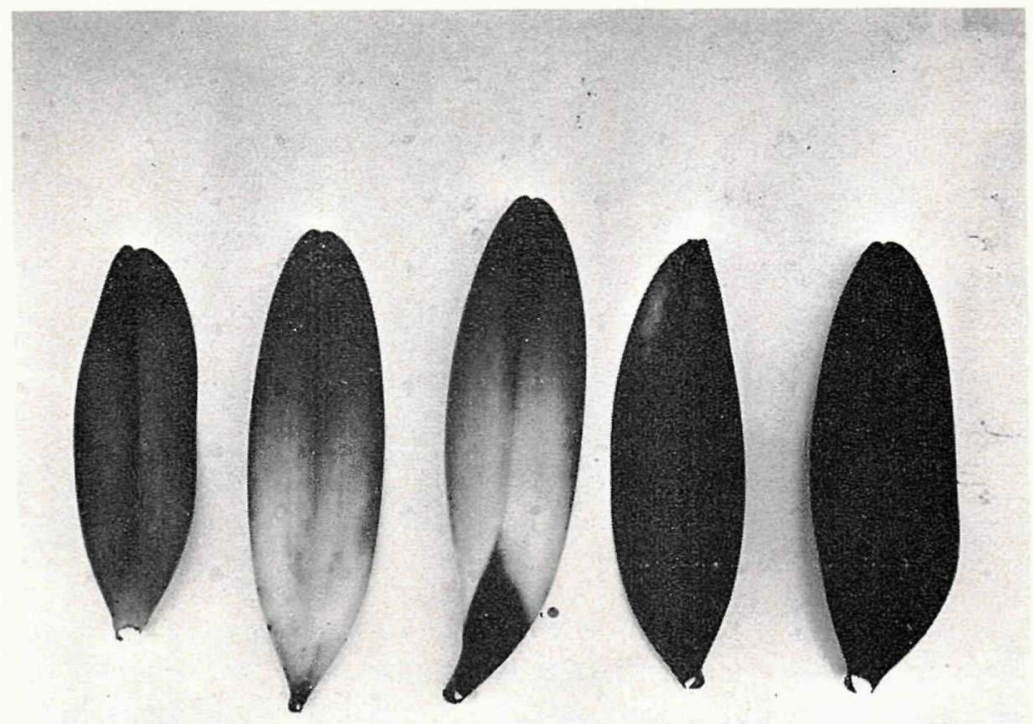

Frg. 8.-Catleya Bowringiana inoculated with Pythium ultimum. Note development of lesion from the base of the leaf up. 


\section{...... CONTROL $2 \pi$}

In diseased plants, infected pseudobulbs were removed. The plants were then treated by spraying with Parzate and Dithane Z-78 (2 pounds in 100 gallons water) every other week. Other plants were sprayed with Bordeaux (2-3-50) and Copper A Compound (2 pounds in 100 gallons). Some of the sprayed plants were left outdoors and no further symptoms of the disease were observed for 8 months.

Other plants were similarly treated but sprayed with water. In this instance, the orchids were placed in greenhouse kept at a relative humidity of 50-60 percent. No indication of the disease was observed under this dry environment. Plants artificially infected but not treated, and left in the greenhouses showed no spreading of the infection to other pseudobulbs or leaves.

Infected plants kept outdoors in a high relative humidity (80 to 90 percent) succumbed to artificial infections.

\section{LITERATURE CITED}

1. Rosséti, V., 1943, O. Biológico 9 : 201-05.

2. Porter, J. N., 1943, Ciencia y Técnica $1: 15-6$.

3. Limber, D. P., 1946, Pl. Dis. 30: 89.

4. Ark, Peter A., and Middletox, Johx T., 1949, Phytopath. 39 : 1061-64. 